pale in colour, soft in consistency, and to resemble in its general characteristics the new growths already observed. Externally the larynx and trachea appeared healthy.

The abdominal viscera, with the exception of the kidneys which were enlarged and congested, were to macroscopical examination apparently healthy; the mesentery was loaded with fat. On removing the scalp the outer table of the skull was found to be eroded by new growths. (Fig. 1.) The latter were of a dark maroon colour and jelly-like in consistency; they ranged from the size of a pea to at least three inches in diameter, the skull being literally riddled; there were 16 erosions of the outer table visible, all these being of fair size. The growths had apparently originated in the cancellous tissue of the bones and extended laterally between the external and internal tables of the skull, tending to thin them, and in some cases going through the bone. Dependent on the stage and direction of the growth, the tumours could be divided into three varieties-namely: (1) those growing between the two layers of the skull ; (2) those eroding the outer table and invading the scalp; and (3) those growing inwards invading and infiltrating the dura mater, though not penetrating it nor affecting the brain tissue; these latter were situated for the most part in the middle line and tended to obstruct the lumen of the superior sagittal (longitudinal) sinus. (Fig. 2.) The brain and spinal cord exhibited no departures from the normal. The cavities of the long bones in the neighbourhood of the fractures were found to be occupied by growth similar to that found in the skull bones, the compact tissue being in places very thin or entirely absent, the surrounding tissues forming a capsule for the tumours. In the case of the femur there was a tendency to so-called expansion of the bone. The shafts of the affected phalanges, excepting for a few fine spicules of bone scattered over the surface of the growth, had disappeared, leaving only the articular ends of the bones. It will be seen that the metastases, with the exception of that found in the trachea, occurred, as far as could be ascertained, only in connexion with bony tissue. Microscopical examination, made some months previous to the appearance of secondary growths, of portions of the tumour removed from the nasopharynx and nostril, although at the time not absolutely conclusive, gave rise to grave suspicions as to malignancy.

Mr. L. Stanley Dudgeon, of St. Thomas's Hospital, who very kindly undertook the microscopical exa. mination of the tumours, reported that the growth exhibited all the characteristics of a round-celled sarcoma.

Parkhurst.

Dr. Robert P. Dawson, J.P., who is a councillor of the borough of Newcastle-on-Tyne, has been selected as the new sheriff for the ensuing year.

Donations and Bequests.-The late Mr. John Murray, of Dublin, has bequeathed nearly the whole of his personal estate, valued at $£ 19,000$, to the hospitals of Dublin in equal shares. - By the will of the late Mrs. Eliza Dixon, of Clifton Down, Bristol, the Middlesex Hospital will receive $£ 1050$ for a cancer bed in the new ward, to be called the "Thomas Dixon" bed, and £1050 for a cancer bed, to be called the "Eliza Dixon" bed.--The late Rev. William Ridge Greenhill has left $£ 200$ and one-third of his residuary estate to the National Hospital for the Paralysed and Epileptic, Queen-square, of which he was chaplain.-King Eäward's Hospital Fund for London will recejve $£ 500$ under the will of the late Mr. James B. Sharp, of Reigate.

\section{A CASE OF MEDIASTINAL PLEURAL EFFUSION.}

BX ALEXANDER ROSE, M.D. ABERD.

Extensive pleural effusion limited to the medi. astinum is a rare disease. So far as I am aware the only text-book that gives a detailed description of mediastinal pleurisy is that of Dieulafoy. The following case shows very little resemblance to those recorded by him and is possibly unique.

The patient, who died suddenly five days after I saw him for the first time, was a thin, sallow. complexioned man, 52 years of age. He gave a history of gradually increasing weakness, wasting, and dyspnoea of at least 12 months' duration. $\mathrm{He}$ had never been a robust man, having been for many years subject to slight attacks of bronchitis, but during the past 29 years, which were spent in one situation, his longest absence from work on account of illness amounted to only three days. One of his children was said to have died in infancy from "consumption." About six weeks before his last illness his feet had been swollen for a few days, especially in the evenings. He complained princi pally of dyspnoea. There was no cough or expectoration. He preferred to lie on his back with the head raised, as the breathing became troublesome if he lay on either side. The pulse was 84 and feeble; respirations short, and varying from 24 to 30 per minute; temperature normal.

On examination of the chest it was found that the measurements of the two sides were equal. The right side was dull to percussion from the base to the third rib anteriorly, and from the base to the spine of the scapula posteriorly. The dulness was most marked at the base, gradually diminishing in intensity from below upwards. The apex was resonant in comparison with the rest of the same side, but dull when compared with the left side. The outline of the dulness was unaltered by change of position. Respiratory sounds were absent at the base of the lung. At the angle of the scapula they were heard faintly, and from there upwards they increased in intensity till at the apex they were loud and bronchial in character. Vocal resonance and fremitus were absent over the lower half of the lung. The lower limit of liver dulness was two inches below the ribs in the right nipple line. The veins over the right side of the chest were slightly dilated. The whole of the left side of the chest was hyperresonant on percussion. In the upper part the resonant area reached to the right border of the sternum. The superficial cardiac dulness was absent, and the apex beat of the heart could not be felt. On auscultation the point of maximum loudness of the heart sounds was in the normal position of the apex. There were no enlarged glands and the urine contained neither sugar nor albumin.

A provisional diagnosis of tumour of the lung with pleuritic effusion was made, and an exploratory needling was recommended. The patient absolutely refused to allow this to be done, and so terrified was he at the very idea that his wife considered his death to be due to fright.

On post-mortem examination it was found that the right lung was adherent to the chest wall all round. In a cavity bounded by the diaphragm below, the mediastinal pleura internally, and the compressed lung in other directions, were $80 \mathrm{oz}$. of serous fluid which coagulated spontaneously. 
The pleura covering the diaphragm and that covering what had evidently been the diaphragmatic surface of the lung were each nearly half an inch thick owing to the deposition of layers of fibrinous lymph. In the apex of the right lung there was a caseous mass of about the size of a walnut, while scattered through the lung were numerous miliary tubercles. The left lung was emphysematous and also contained miliary tubercles. The heart was very slightly, if at all, displaced.

In the article alluded to above Dieulafoy gives a description of five cases observed by himself or others. In all of these the fluid was purulent. Three were pneumonic in origin, and in two of these the abseess opened into a bronchus, one patient coughing up $3 \mathrm{oz}$. and the other $6 \mathrm{oz}$. of pus. In one tuberculous case a cavity of the size of an orange was found. It communicated with the right bronchus, and its boundaries were the vertebral column, ribs, and root of right lung. In the fifth case an encysted empyema in front of the hilum of the lung contained $10 \mathrm{oz}$. of pus. The patient was supposed to be suffering from chronic phthisis, but no tuberculous lesion was found. He also quotes Laennec as having seen circumscribed cases of pleural effusion between the inner surface of the lung and the mediastinum, the effusion being only "one or two spoonfuls" in amount.

According to Dieulafoy mediastinal pleurisy begins like an acute febrile attack with pain, fever, cough, and dyspncea. This mode of onset along with the absence of glandular enlargement helps to distinguish it from mediastinal tumour. If the encysted fluid travels towards the lung and affects the mediastinum only to a slight extent the signs are uncertain and the diagnosis remains indefinite. If it travels towards and exerts pressure on the mediastinal contents the collection of symptoms known as the "mediastinal syndrome" is found. These symptoms are dyspnoea, stridor, and sucking in of the chest wall, dysphagia, distension of the veins of the chest, fits of coughing and suffocation, and hoarseness, dysphonia, and spasm of the glottis. They are caused by pressure on the trachea, cosophagus, azygos vein, and the pneumogastric and recurrent laryngeal nerves, and all or only some may be present. As a rule the heart is little affected.

The principal points of interest in the above case are the position and large amount of the effusion, the slight inconvenience caused to the patient during the many months it must have taken to accumulate, and the almost complete absence of pressure symptoms. The post-mortem findings suggest that the effusion was originally an encysted diaphragmatic one, and that its extension to the mediastinum occurred comparatively late. The lung, being tuberculous and fixed, would offer less resistance to the pressure of the fluid than the mediastinal contents and the comparatively healthy left lung offered.

It is difficult to see how the patient could have been benefited in any way by surgical intervention, If aspiration had been attempted it is doubtful whether the needle would have reached the fluid owing to the thickness of the intervening lung. If one had succeeded in drawing off any considerable quantity of the fluid, most probably another case would have been added to the list of sudden deaths which have occurred during the operation of paracentesis of the chest.

South Norwood, S.E.

\section{Clinital atotes:}

MEDICAL, SURGICAL, OBSTETRICAL, AND THERAPEUTICAL.

\section{NOTES ON FOUR CASES OF SPLENECTOMY FOLLOWING RUPTURE.}

By Robert Cox, M.B., B.CH. R.U.I., FEDERATED MALAY STATES GOVERNMENT SERVICE.

IN the June number of the Indian Medical Gazette appears a report of splenectomy following rupture, in which the writer lays stress on three points: 1. "The long period (34 hours) between the injury and the operation, an extraordinary length of time for a ruptured spleen to exist without a fatal result," and he explains it by the fact that the hæmorrhage was controlled by two injections of morphia gr. $\frac{1}{4}$ administered at intervals before operation. 2. Sepsis due to infection of silk owing to hurry. 3. The persistence of malaria in the blood after removal of the spleen. I venture to send you some notes on four similar cases.

CASE 1.-At 2 P.M. on May 7th, 1914, in Ipoh Hospital I examined a Pathan who had been run over by his own bullock cart at 2 A.M. on the previous day (interval 36 hours) the wheels of the cart, which was loaded, had passed over his back and left arm, fracturing his humerus. He complained of pain in the abdomen, which was tender and slightly rigid, the respirations were rapid, and the pulse-rate 144. On opening the abdomen through the left rectus I found the peritoneal cavity full of blood and the spleen torn in its long axis practically into halves, which were held together only by a small portion of capsule. A second incision was made outwards at right angles to, and at the upper end of, the first incision, and the spleen, which was three times the size of the normal, removed, after which the cavity was irrigated with saline and the abdominal wall sewn up with through-and-through silkworm gut sutures. Salines were given intracellularly during the operation and hypodermic injections of liq. strych. $m v$. and adrenalin $m x x$. Immediately after operation morphia gr. $\frac{1}{2}$ was injected, a further gr. $\frac{1}{4}$ being given at 8 P.M., and repeated at 8 A.M. the next morning. On the night of operation $I$ was unable to count his pulse, but the next morning it was 134 and in the evening 120 ; on the third day the pulse was 90 and on the fourth day 78. A differential blood count two months after operation showed: polymorphonuclears, 29.5 per cent. ; small mononuclears, 32.5 per cent. ; large mononuclears, 17 per cent.; eosinophiles, 14 per cent. ; mast cells, 3 per cent.; and transitionals, 4 per cent. At this time the abdominal wall appeared perfectly sound with no tendency to hernia.

The points I would draw attention to are: (1) The long interval between the accident and the opera. tion (36 hours), no morphia having been used; (2) the absence of sepsis; I consider the time spent on sterilisation was fully justified, all stitches being removed on the tenth day; and (3) the presence of malaria after operation. I fail to see why removal of the spleen should affect the per. sistency of malaria.

CASE 2.-On April 21st, 1912, at 9.30 P.M., a Chinaman, who had been injured in a mining accident 13 hours previously, was admitted to Kampar Hospital complaining of great pain in the abdomen. His pulse was 120 , the abdomen was tender but not rigid, and he was unable to lie down. I performed a supra-umbilical laparotomy through the left rectus and removed a ruptured spleen weighing $2 \mathrm{lb}$.; after operation the patient was treated with intracellular salines with adrenalin and injections of strychnine. He died eight hours after operation.

CASE 3.-On July 2nd, 1912, at 2 P.M., I examined a Chinaman in Kampar Hospital who 'said he had been 